\title{
Why stable populations of conserved bird species may still be considered vulnerable: the nihoa finch (telespiza ultima) as a case study
}

\begin{abstract} of the species, through a focus on addressing objectives:

i. Understand predictability of population data with an SBC;

ii. Assess changes in bird sightings;

iii. Consider implications for future monitoring;

iv. Infer strategies for species management.
\end{abstract}

Conservation management requires practical and resource efficient monitoring of endangered species to enable protection of vulnerable populations and habitats. System Behaviour Charts (SBC) present longitudinal data to identify changes over time to predict future status of the ecosystem and provide insights which support decisionmaking, planning and recovery actions. This study presents an analysis of population counts of Nihoa finch (Telespiza ultima), an endemic bird of the Hawaiian Islands, using Systems Behaviour Chart methodology. The study aims to understand the predictability of population data and consider the implications for future monitoring

The results revealed that despite the finch population being stable over 33 years, the lower natural limit remains below zero suggesting that the species is still at risk of extinction. In practical terms, management of the species requires adjusting the status so that lower limits in SBC analysis rise above zero. When such a status is achieved, conservation managers can consider how to maintain low level monitoring of the species (enabling resources to be directed to other concerns), without neglecting the species. Comparisons are given with SBC analysis of other bird species. Imperatives for managing the Nihoa finch include habitat recovery (including pest control), captive breeding, and translocation to create new sub-populations.

Keywords: conservation, Hawaii, statistical process control, population, systems thinking, decision making, management
Volume 3 Issue I - 2018

\section{Akshita V Pungaliya, Samuel C Leslie, Simon A Black}

Durrell Institute for Conservation and Ecology, University of Kent, United Kingdom

\section{Correspondence: Simon A Black, Durrell Institute of Conservation and Ecology, School of Anthropology and Conservation, Marlowe Building, University of Kent, Canterbury, Kent, United Kingdom, Tel +44 (0) I 227 827056, Fax +44 (0) I 227} 827289,Email s.black@kent.ac.uk

Received: December 22, 2017 | Published: January 19, 2018
Abbreviations: SBC, systems behavior chart; UNL, upper natural limit; LNL, lower natural limit; UWL, upper warning limit; LWL, lower warning limit; MR, moving range; XMR, average moving range chart

\section{Introduction}

Islands host a high percentage of endemic species due to their ecosystems having evolved in isolation. ${ }^{1}$ In the absence of natural predators and resistance to alien diseases, the flora and fauna of islands are considered more fragile than mainland species and prone to impacts from non-native species. ${ }^{2}$ The ecosystems of the Hawaiian Islands, one of the world's most isolated archipelagos, have a diverse and highly endemic wildlife, ${ }^{3}$ first challenged 1200 years ago by rats, pigs and dogs brought by Polynesians, followed a thousand years later by European colonists with more rats, cattle, sheep, goats, cats, parasites and diseases. ${ }^{4}$ Numerous Hawaiian species are declining and many, including more than half of its endemic birds, ${ }^{5}$ have fallen to extinction due to anthropogenic factors. The status of decline and sustainability of various bird populations remains a current concern. ${ }^{6}$

Conservation management often requires interpretation of limited data on the species or ecosystems of concern. ${ }^{7}$ In practice monitoring effort is constrained by resource limitations, so there is value in options that allow re-deployment of intensive monitoring (including reduction or even cessation). System Behaviour Charts (SBC), developed from statistical concepts established since the $1920{ }^{\prime} \mathrm{s}^{8,9}$ provide insights into the dynamics of natural systems by representing longitudinal plots of existing datasets or newly sampled data. ${ }^{10,11}$ Various studies have used SBC to identify changes in ecological systems, including population levels for specific species. ${ }^{8,10-12}$ Analysis of a metric, or a series of metrics, on charts of longitudinal time-series data allows a deeper consideration of specific patterns, including improvements and declines, which can be differentiated from fluctuations derived from underlying statistical 'noise', or patterns caused by seasonal cycles, geography or other attributable phenomena. In conservation three situations are of particular interest; stable, unstable and changing systems. ${ }^{8}$ A fourth scenario in conservation is where a stable system occurs whereby it remains unacceptably vulnerable to stochastic events. An example of this would be a population of a species where, statistically speaking, a zero population could be reasonably predicted from the data. This type if inference can only be gained from looking at patterns of longitudinal data over time.

This case study presents how SBC provides helpful insights into bird population management, using the case of the endemic Nihoa finch 
(Telespiza ultima), which is found only on Nihoa in the Northwestern Hawaiian Islands. ${ }^{13}$ The species is currently listed as Critically Endangered by the IUCN ${ }^{14}$ and is present across available habitat on Nihoa. Despite suggestions that the population improved in the 1990s and more moderately since $2001,{ }^{15}$ fluctuating counts and large errors associated with estimates and monitoring methods have made it difficult to determine the population trend, ${ }^{14,15}$ with complications arising from detection of a highly mobile species, sightings within differing vegetation, and observation error. The ecosystems on Nihoa have proven vulnerable to recent encroachment by alien species (plant, animal and disease) and the finch population may be affected by limitations in the habitat on Nihoa. For example, Chenopodium oahuense is a plant extensively used for nesting and cover by Nihoa finch ${ }^{15,16}$ but, alongside other native plants, has been devastated by the non-native grasshopper Schistocerca nitens. ${ }^{16}$ Debate surrounds whether the grasshopper should be considered invasive, or reflects occasional visitation and thereby regulates vegetation as naturally as, for example, forest fires. ${ }^{14,16}$ This raises the question of whether the finch population, despite its stability, is fundamentally vulnerable (e.g. to cyclical insect infestation of habitat) and whether conservation strategies should reflect this situation. The study examines population data from 1979-2012, focused on the following objectives:

a. Analyze population data to understand predictability using an $\mathrm{SBC}$;

b. Assess changes, if any, in bird sightings;

c. Consider implications for future monitoring;

d. Infer relevant strategies for species management.

\section{Data analysis}

Population data from 1979 to 2012 for the Nihoa finch were derived from literature. ${ }^{15}$ For SBCs, 20 or more data points provide useful insight ${ }^{8,17}$ when plotted on a chart alongside calculated limits (Figure 1). The mean $(\overline{\mathrm{x}})$ of the population counts was plotted as the central line. As in previous ecological studies ${ }^{10,11}$ the standard deviation $(\sigma)$ was used to calculate four control limits previously discussed in literature: ${ }^{12}$ Upper Natural Limit, $\mathrm{UNL}=\bar{x}-3 \sigma$; Lower Natural Limit, $\mathrm{LNL}=\bar{x}-3 \sigma$; Upper Warning Limit, $U N L=\bar{x}-3 \sigma$ ; Lower Warning Limit, $L W L=\bar{x}-2 \sigma$. For further comparison, additional upper and lower limits used in average moving range (XMR) charts were also plotted using the two-point moving range, since such limits can be more sensitive in un-homogeneous data sets, ${ }^{9,17}$ providing an Upper Limit $X M R=\bar{x}-2.66$ (MR) and Lower Limit $X M R=\bar{x}-2.66$ (MR).

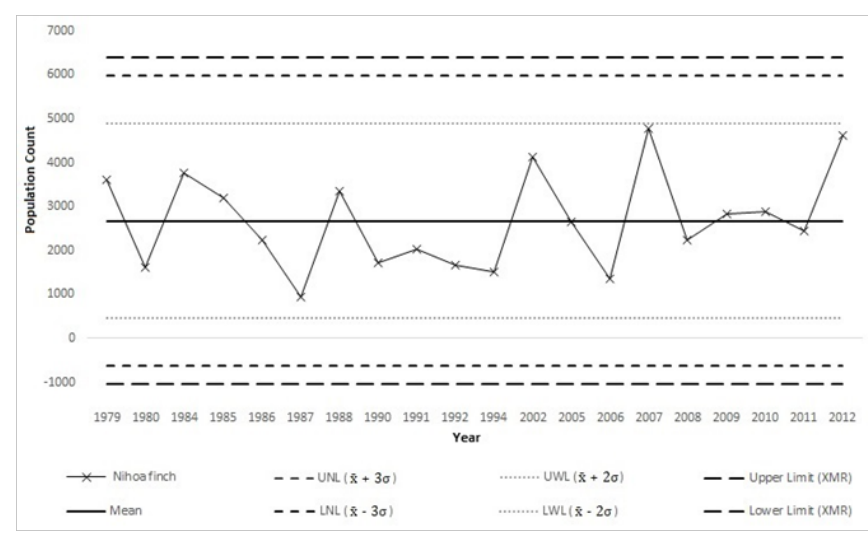

Figure I Systems Behavior Chart of population of Nihoa finch (Telespiza ultima) on Nihoa Island, Hawaii, 1979-2012,15 shows lower limits derived from $\overline{\mathrm{X}}-3 \sigma$ and average moving range (XMR) below zero.

\section{Results}

The position of data relative to the empirically-derived limit lines enables differentiation of routine variations from exceptions and informs judgment of whether a system is predictable and stable, or not, using empirically-derived rules. The SBC of population counts for the Nihoa finch revealed that throughout the period from 1979 to 2012 the population remains stable within natural limits (Figure 1), displaying a steady state (i.e. stable system) in line with SBC rules 1-7. However, the eighth SBC rule for conservation requires that where a LNL falls below an acceptable zero (e.g. a population count of zero indicates extinction, so is definitively unacceptable) then the system should be considered as being of concern. In the case of the Nihoa finch, despite a healthy mean population of approximately 2500 , both sets of lower limits calculated at $\bar{x}-3 \sigma$ and $\bar{x}-2.66$ (MR) fall below zero (Figure 1). This indicates that the species may fall to extinction in any future time so continued monitoring is required to avoid any such occurrence.

\section{Discussion}

The SBC for the Nihoa finch population data empirically illustrates how even apparently stable systems can be identified as fundamentally vulnerable. The population of Nihoa finch is relatively large, so while there is no call from either $3 \sigma$ or XMR limits for immediate action, the below-zero lower limits indicate that regular monitoring is required to anticipate existing vulnerability. Figure 1 demonstrates that XMR limits, set at $\bar{x}-2.66$ (MR), are even more sensitive to the situation and suggests the latter may be more sensitive to un-homogeneous ecological data setting more stringent requirement to improve the system. This might require a review of the ecology of the island. At the very least, continued monitoring of the Nihoa finch must continue to instigate future action if needed. Similar species vulnerability has been observed ${ }^{8}$ in an otherwise recovered population of Puerto Rican amazon parrot (Amazona ventralis vittata) which despite significant population increase and stabilization is significantly impacted by hurricane events. ${ }^{18}$ The Precautionary Principle ${ }^{19}$ suggests that in these instances it would be prudent to carefully manage species populations and habitats since a lower limit below zero indicates that the species may fall to extinction in any future time. By contrast, in cases of stable systems where a population's lower natural limit sits above zero, regular monitoring could be reduced to less intensive, cost-effective approaches, such as investigations of species presence or less frequent population surveys. Since the Nihoa finch population is stable but vulnerable, conservation effort should focus on increasing suitable habitat (to the benefit of other endemic species), possibly including eradication or control of alien insects. It would also be prudent to consider translocation (supported by previously recommended captive breeding $)^{14}$ of a second finch population onto an additional island ${ }^{15,16}$ as part of a widening the habitat range. Re-establishment of the species prehistorical presence on Moloka ${ }^{6} i$ Island $^{16}$ may not be possible due to disease encroachment, but translocation onto smaller islands in the northwestern archipelago have been considered. ${ }^{14}$

New concepts are needed to understand vulnerabilities of species in relation to ecosystem stability and population status ${ }^{20}$ and this must go beyond experience-based measures of viability. Reliance on perceived declines such as trends or point-to-point variance (on metrics such as population size, structure, range, demographics, food or habitat availability) relies on assumption since it does not consider variation over time. Prioritization of scarce conservation resources involves decision-making in the face of numerous challenges. ${ }^{7}$ The SBC is an accessible method ${ }^{11}$ which informs relevant monitoring strategies, encouraging either a continuous approach (e.g. weekly, seasonal or 
annual sampling) or occasional interventions to assess population status. System Behavior Charts offer a 'boundary science'21 that bridges the gaps between research and management decision-making, providing a more complete understanding of available data needed to conserve species.

\section{Conclusion}

It has been noted that many monitoring programs lack empirical definition of tolerable levels of ecological change that would prompt management action when most necessary. ${ }^{22}$ The IUCN have currently recognized the Nihoa finch as Critically Endangered due to its range restriction and vulnerability to accidental introduction of alien predators, pests, or disease, or a stochastic event such as a hurricane or forest fire. ${ }^{14}$ However, if the impact of recovery actions for this species is reflected, over time, in a population count demonstrated through SBC with a lower natural limit rising above zero, then progress will have been achieved suggesting that the species can become less vulnerable to such potential threats. This type of longitudinal Systems Behaviour Chart analysis, which is not possible with other charting or predictive methods, enables conservation scientists and decision-makers to get a stronger empirical understanding of species vulnerabilities to threats such as storms, fire or alien species invasion. To support this, further investigation should examine the sensitivity of calculated natural limits based on both moving range and standard deviation, to inform SBC design and application. Systems behavior charts provide an empirical understanding of stability and vulnerability, which conservation managers can use to define actions that will achieve, through cost-effective strategies, future status in species' populations that will more likely withstand unpredictable, stochastic events.

\section{Acknowledgements}

The authors acknowledge $\mathrm{J}$ Groombridge and $\mathrm{G}$ Rodda for recommending reference data sources.

\section{Conflict of interest}

The authors have no financial interest nor conflict of interest related to research in this article.

\section{References}

1. Kier G, Kreft H, Lee TM, et al. A global assessment of endemism and species richness across island and mainland regions. PNAS 2009;106(23):9322-9327.

2. Simberloff D. Why do introduced species appear to devastate islands more than mainland areas. Pacific Science. 1995;49(1):87-97.

3. Pratt TK. Conservation Biology of Hawaiian Forest Birds: Implications for Island Avifauna. UK: Yale University Press; 2009.

4. Scott JM, Mountain S, Ramsey FL, et al. Forest bird communities of the Hawaiian Islands: their dynamics, ecology, and conservation. Cooper ornithological society. USA: Allen Press; 1986.
5. Scott JM, Conant S, Van Riper C. Evolution, Ecology, Conservation and Management of Hawaiian Birds. Cooper ornithological society. USA: Allen Pres; 2001.

6. Rozek JC, Camp RJ, Reed JM. No evidence of critical slowing down in two endangered Hawaiian honeycreepers. Plos One. 2017;12(11):e0187518.

7. Black SA, Groombridge JJ, Jones CG. Using Better Management Thinking to Improve Conservation effectiveness. ISRN Biodiversity. 2013;784701:1-8.

8. Black SA. System Behaviour Charts inform an understanding of biodiversity recovery. International Journal of Ecology. 2015;787925:16.

9. Shewhart WA. Economic control of quality of manufactured product. USA: ASQ Quality Press; 1931.

10. Pungaliya AV, Black SA. Insights into the Recovery of the Palila (Loxioides bailleui) on Hawaii through Use of Systems Behaviour Charts. IJAWB. 2017;2(1):1-2.

11. Leslie SC, Blackett FC, Stalio M, et al. Systems Behavior Charts of Longitudinal Data Inform Effective Management in Marine Conservation. JAMB. 2017;6(5):1-3.

12. Gove, AD, Sadler R, Matsuki M, et al. Control charts for improved decisions in environmental management:a case study of catchment water supply in south-west Western Australia. Ecological Management \& Restoration. 2013;14(2):127-134.

13. Bryan WA. Description of Telespiza ultima from Nihoa Island. The Auk. 1917;34(1):70-72.

14. Birdlife International. The IUCN Red List of Threatened Species. UK; 2016.

15. Gorresen PM, Brinck KW, Camp RJ, et al. State-space modeling of population sizes and trends in Nihoa Finch and Miller bird. The Condor. 2016;118(3):542-557.

16. Latchininsky AV. Grasshopper outbreak challenges conservation status of a small Hawaiian Island. Journal of Insect Conservation. 2008;12(34):343-357.

17. Wheeler DJ. Understanding variation: the key to managing chaos. 2nd ed. USA: SPC Press; 2000.

18. Wunderle JM. Pre-and post-Hurricane fruit availability: Implications for Puerto Rican parrots in the Luquillo Mountains. Caribbean Journal of Science. 1999;35 (3-4):249-264.

19. Foster KR, Vecchia P, Repacholi MH. Science and the precautionary principle. Science. 2000;288(5468):979-981.

20. Black SA, Meredith HM, Groombridge JJ. Biodiversity conservation: Applying new criteria to assess excellence. Total Quality Management \& Business Excellence. 2011;22(11):1165-1178.

21. Cook CN, Mascia MB, Schwartz MW, et al. Achieving conservation science that bridges the knowledge-action boundary. Conservation Biology. 2013;27(4):669-678.

22. Davis J, Brock M. Detecting unacceptable change in the ecological character of Ramsar wetlands. Ecological Management and Restoration. 2008;9(1):26-32. 